\title{
Where to Now? Fourteen Characteristics of Teachers' Transition into Innovative Learning Environments
}

\author{
Wesley Imms and Marian Mahat
}

\begin{abstract}
This chapter places the preceding papers into a wider context. As part of the Innovative Learning Environment and Teacher Change (ILETC) project, seven Transitions symposia were held in five cities across Australasia, Europe and North America during 2017, 2018 and 2019. Each aimed at investigating how teachers adapt to innovative learning environments. The resulting accumulation of approximately 150 papers by graduate researchers and research groups, of which this book's chapters are a sample, constituted a reasonable representation of international thinking on this topic. When added to three years of ILETC case studies, surveys, systematic literature reviews and teacher workshops, the project team was able to identify consistent patterns in teachers' spatial transition actions. This chapter places the material of this book within that larger picture, specifically in terms of one project output-the development of a Spatial Transition Pathway. The Pathway emerged from these data and can be seen as an output of the material sampled in previous chapters. Certainly, the considerable work teachers had been doing to re-conceptualise their pedagogies for new spaces (done both intentionally, and at times, without realising) deserved to be mapped as a resource for others undertaking this journey. This chapter makes the case that while each teacher or school's journey from traditional to 'innovative' spaces is unique, there exists some common issues that most seem to face at some time, in some way. It provides a description of fourteen 'grand themes' that appear commonly through the data and describes how these can be organised in a way that provides temporal and theme-based strategies and tools, developed by fellow educators to assist in this transition. This final chapter leads the reader to consider 'where to now'? It celebrates the fact that teachers have enormous capacity to work out how to utilise innovative learning environments well and provides a framework for evidence-based actions into the future.
\end{abstract}

W. Imms $(\bowtie) \cdot$ M. Mahat

The University of Melbourne, Melbourne, Australia

e-mail: w.imms@unimelb.edu.au

W. Imms and T. Kvan (eds.), Teacher Transition into Innovative Learning Environments, https://doi.org/10.1007/978-981-15-7497-9_25 


\section{Context}

The consistent messages from the preceding chapters are as follows: innovatively designed spaces, intended to broaden the skills developed by all students, now exist in reasonable numbers. Like much innovation, they are a creation and development of an idea-more a work in progress than a proven solution. For 'success' they require consistent, focused, well-supported actions by designers, administrators, teachers, students and parents over a period of time; the suggestions of success they provide warrant sustained effort. In short, we are all participating in the practice of iterationwe are building success from success and learning from what does not work as well.

Research, the generation of new knowledge, is a critical part of this process. However, it is also a proven process of development; through applied research, we plan and implement strategies, we gather robust data on what occurs, we analyse logically, report findings in a range of ways, then use that to conceptualise the ways we need to proceed in the future to attain sustainable success. This process means every now and then we must nail our colours to the mast. We declare 'this is what we now know' and encourage our findings to be used so we can progress to another layer of analysis and development.

This then is the context for what follows in this final chapter. The increasing body of research on use of innovative learning environments as sampled in this book's chapters has been collated into a framework for actual use. The chapter will briefly overview the analysis methods that lead to the Pathway design (briefly, because a comprehensive account is being made available elsewhere). It will focus in more detail on the actual structure of the Pathway and conclude with an example how it might be used. This is iterative design; utilisation of the resource is to follow.

\section{Developing the Transition Pathway}

As one example of the extent of investment in innovative learning environments, Australia has seen over $\$ 16 \mathrm{~B}$ invested in school buildings over the past nine years (Commonwealth of Australia, 2010). It is estimated Australia alone needs to add about 750 new schools to meet a growing population (Goss, 2016). This need is creating an infrastructure investment of up to AUD\$11B (Holland, 2017), the total of this investment is considerable for a country of about 25 million people. Much of this investment is in what are called innovative learning environments, flexible and purposeful designs driven by a national policy to foster graduates who can excel at twenty-first-century thinking. How do we move from developing graduates who can perform routine tasks well, to those who have these skills but can also excel at interpersonal, non-routine ways of working? Australia, like many countries around the world, believes the design of schools plays some part in this. But it must be 
emphasised-this investment is not about the buildings, it's about what happens in those spaces.

Project ILETC's wish is to better understand how these innovative learning environments improve student learning experiences. In this project, we unapologetically focus on teachers. We know that good teaching is the single largest influence on improving student learning (Hattie, 2009, 2012). ILETC wants to help good teachers teach even better. One way of doing this is by building evidence and resources that help them realise that learning environments like these can be a vital, key part of their pedagogical repertoire.

So, by 'student educational experiences' we mean improving measurable learning outcomes, but even more critically we look to the development of those qualities considered vital when equipping our students to do well in a rapidly changing society: collaboration and communication skills; creative and critical thinking skills. Our belief is that these are qualities that are developed effectively within the phenomenon of student deep learning (Mahat, Bradbeer, Byers, \& Imms, 2018).

And by 'helping teachers teach better' we look to those mind frames that teachers utilise when they engage in practices seen to have the greatest effect on quality learning outcomes for students. There is a difference between an experienced teacher, who knows what to do, and an expert teacher, who maximises student learning. Research shows the latter occurs when a set of ways of thinking are employed-the mind frames (Hattie, 2012; Mahat et al., 2018).

So, we would like you to keep these two concepts at the forefront of your thinking as you read further, because ILETC is situated at the intersection of student deep learning, teacher mind frames and the potential of innovative learning environments.

\section{What Did We Do?}

We began by gathering baseline data that has been presented within a myriad of ILETC publications since 2017 and is selectively cited in this chapter and available online at the project's website. The baseline data was required for a number of reasons, but the critical ones were to: firstly gauge the current state of play, and second to test assumptions we carried to the project. Let us focus on the first of these.

What innovative learning environment infrastructure actually exists in Australia and New Zealand? No one, including the large education departments partnering us in this research, could answer that seemingly basic question. Our problem was, how can we suggest ways to help teachers transit into innovative learning environments if we don't know how many exist and in what configurations?

We used The University of Melbourne's Learning Environment Applied Research Network (LEaRN) Typology of Spatial Design ${ }^{1}$ (Fig. 1) to ask this question to over

\footnotetext{
${ }^{1}$ This has been developed over time through various LEaRN projects, but acknowledgement must be made to Drs. Kenn Fisher and Kym Dovey for the original conceptualisation; Dovey, K. \& Fisher, K. (2014). Also to Dr. Pippa Soccio for the graphic representation.
} 

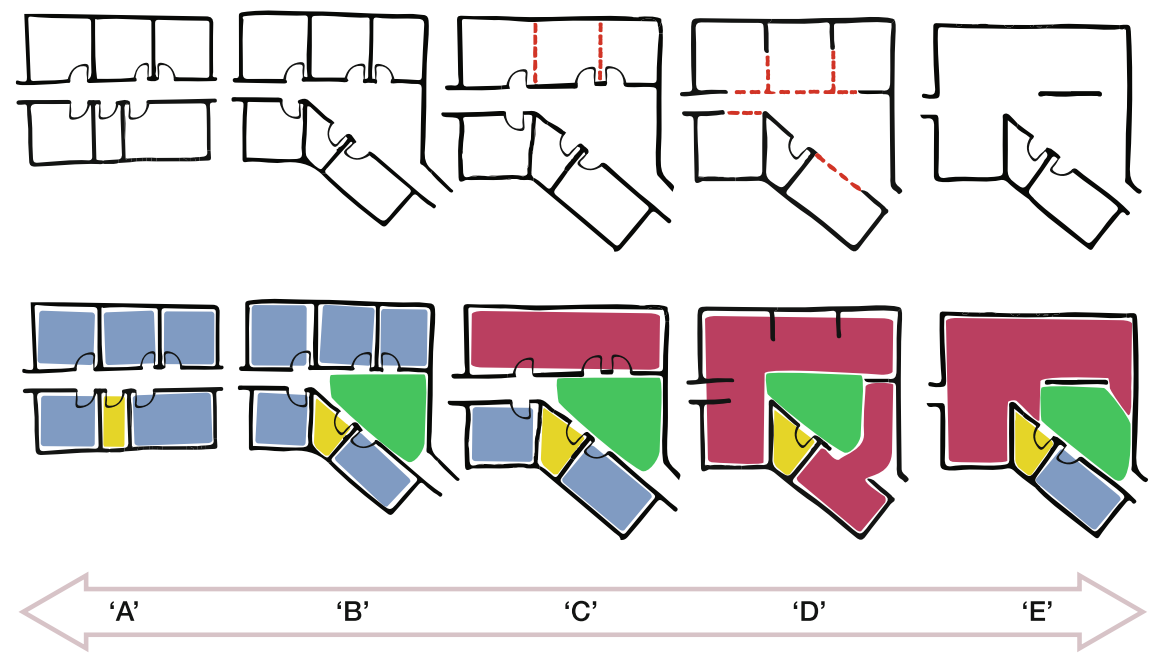

'A'

'B'

'C'

'D'

'E'

TRADITIONAL Learning spaces

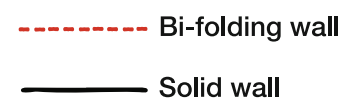

Solid wall

\section{Store room \\ Classroom \\ Street-space}

OPEN-PLAN Learning spaces

Fig. 1 Typology of spatial design (source Imms, Cleveland \& Fisher, 2016. Reprinted with permission from the ILETC project)

a thousand primary and secondary school principals in Australia and New Zealand, discussed briefly in Kenn Fisher's introductory chapter. The left-hand side of the typology identifies traditional cellular classrooms, what we call Type A. The righthand type identifies open plan classrooms, what we call Type E. Between are a set of hybrid types between these two apparent extremes. Results from this first large ILETC survey showed that approximately a quarter of existing teaching spaces in Australia and New Zealand were Types C, D and E, what we'd consider more innovative spaces. The rest were traditional classrooms, some with an adjacent common area.

What types of pedagogies are being employed in these spaces? Again, LEaRN developed a typology showing six types of pedagogy ranging from a traditional teacher-centred approach with tables arranged in rows facing a front, to a pedagogic approach that encouraged students working totally independently with little or no teacher interaction (Fig. 2). What we found was that according to principals, $75 \%$ of teachers in their schools were teaching didactically through teacher-centred instruction (Typology 1 and 2). So, at any given time in Australia and New Zealand, 75\% of students are arranged in traditional settings, facing the front of a room with a teacher talking to them.

We also asked principals what type of learning was happening, and for this we used a scale based on Biggs' surface-to-deep learning characteristics (Biggs, 1987). 


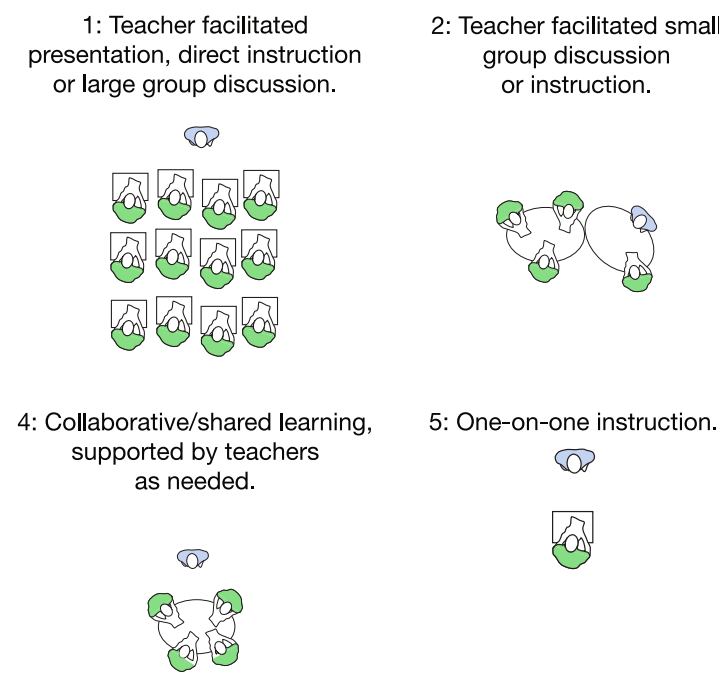

3: Team teacher facilitated presentation, direct instruction or large group discussion.

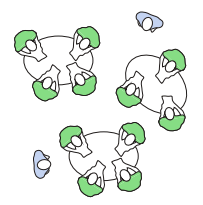

6: Individual learning.

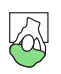

Fig. 2 Typology of teaching approaches (source Imms, W., Mahat, M., Byers, T, \& Murphy, D. 2017. Reprinted with permission from the ILETC project)

This was extended to principals' belief about the qualities evident in that teaching, based on Hattie's visible learning work that produced eight 'mind frames' characteristic of high-impact teaching (Hattie, 2012).

When correlated to the types of spaces in use, we identified a direct and clear trend (Fig. 3); low-impact teaching strategies and surface learning were consistently correlated to traditional classroom designs; high-impact teaching and good deep learning characteristics correlated strongly to Type D and E designs.

This survey is reported in an ILETC Technical Report, available online (Imms, Mahat, Byers, \& Murphy, 2017; Mahat \& Imms, 2020). As too are an additional four 'baseline data' strategies we utilised in that first phase of the project. Apart from Principals' perceptions,

- we asked teachers what they believed about innovative learning environments, using design thinking strategies to structure regional workshops across Australia and New Zealand (Mahat, Grocott, \& Imms, 2017);

- we conducted three Prisma systematic reviews of literature to find out what range of research informed our issue (Bradbeer, Mahat, Byers, \& Imms, 2019; Byers, Mahat, Liu, Knock, \& Imms, 2018);

- we conducted over 30 case studies in schools by our team of seven Ph.D. students, to gain a more objective view of what was happening (see for example, French, Imms, \& Mahat, 2019; Young, Cleveland, \& Imms, 2019);

- we ran seven research symposia in Australia, New Zealand, North America and greater Europe to determine what is occurring beyond our shores (Imms \& Mahat, 2017, 2018a, 2018b, 2019); 


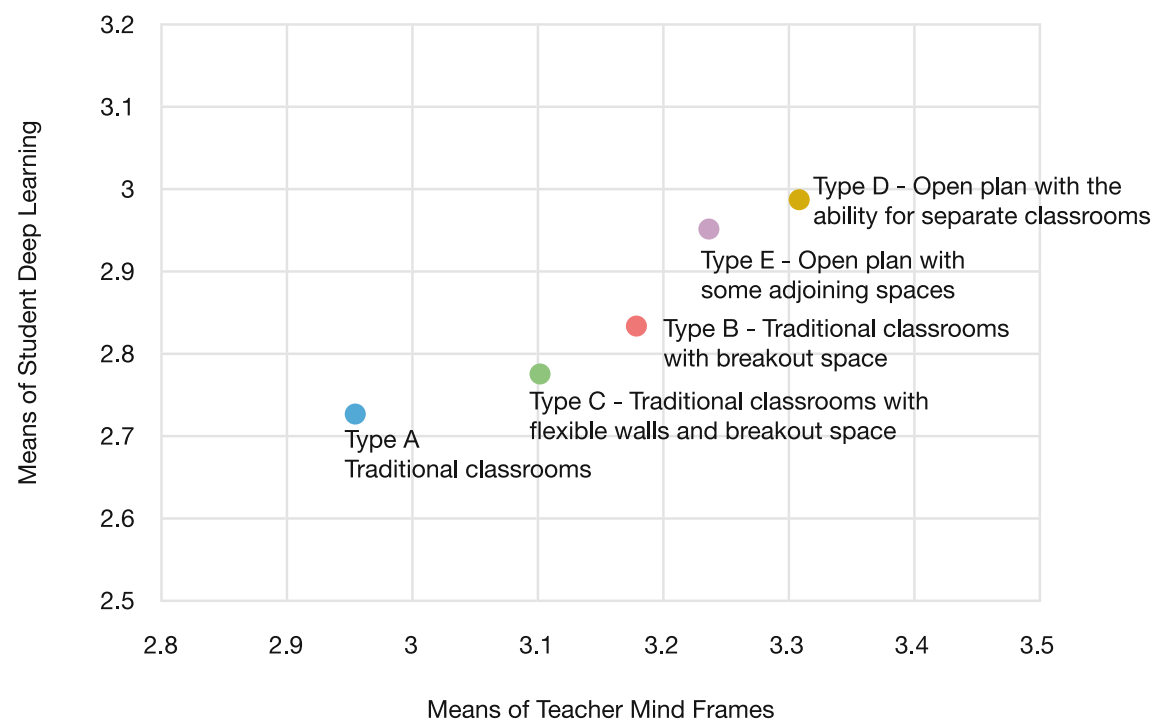

Fig. 3 Means of teacher mind frames and student deep learning categorised by most prevalent learning environment type $(n=822)$ (source Imms, W., Mahat, M., Byers, T, \& Murphy, D. 2017. Reprinted with permission from the ILETC project)

- we conducted industry think tanks in the United States, Australia and England to get a sense of what associated industries believed was occurring (ILETC, 2018).

\section{The Fourteen Grand Themes}

The resulting mass of data collected over a 24-month timespan was analysed for a number of purposes, but a critical one was what we'd now like to focus on for the remainder of this chapter.

What characterises good teacher transition into innovative learning environments?

The first finding was the temporal nature of teacher transition to innovative learning environments (Fig. 4). This was not surprising-solid literature on this topic has consistently argued that teacher use of innovative learning environments is not immediate-it takes time for changes to occur (Bruckner, 1997). ILETC's Spatial Transition Pathway acknowledges this phenomenon and refines it further (Mahat et al., 2019);

- Good transition begins with what we call an early stage where teachers develop knowledge about the upcoming build and conceptualise how they should use it.

- Then comes an occupation stage, that magic period where everything is new, but also a challenging stage where the reality of these quite different environments is made stark. 


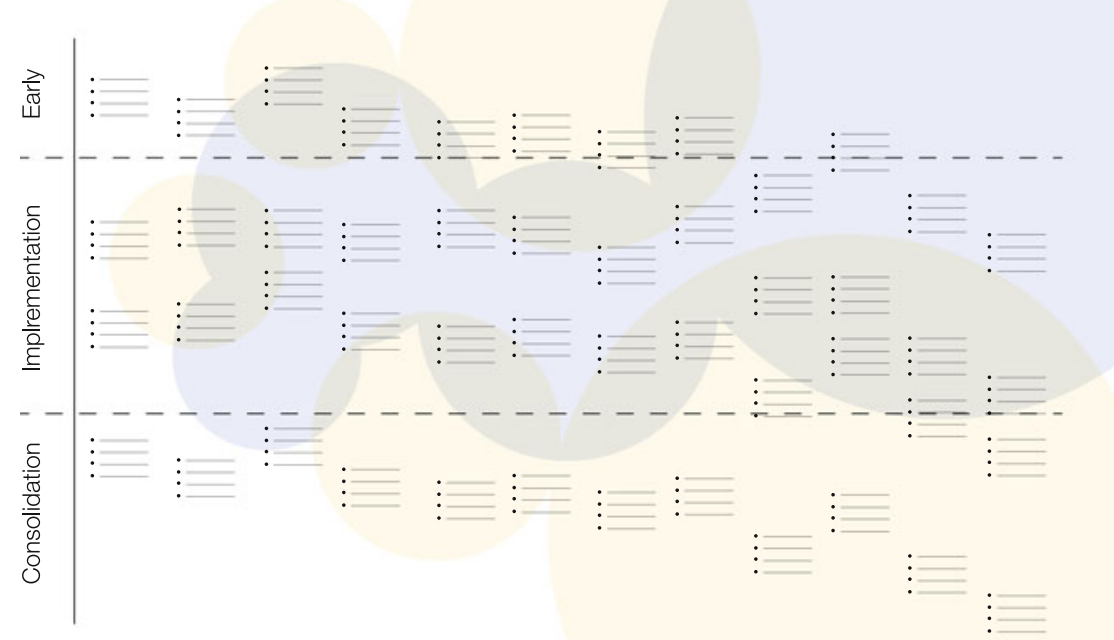

Fig. 4 The transitions pathway, $Y$ axis denoting temporal aspect (Copyright the ILETC project)

- Finally, we have the longer-term inhabitation stage, the many years of use that prove - through experience - if the spaces are meeting the educational vision that brought them into being.

Across these stages our Phases One data allowed us to identify fourteen common characteristics of good transition, what we call out transition grand themes (Fig. 5). We describe these 'grand themes' below although the discussion within is nonexhaustive.

Teachers need TIME to (Mahat et al., 2017)

- Assist in conceptualising new spaces-providing an educational brief that informs the design brief

- Prototype new spatial arrangements

- Experiment with new pedagogies

- Trial collaborative teaching strategies

- Understand what the plans 'mean'.

Teachers need support in working out how old and new TECHNOLOGIES can support their teaching in these spaces (Mahat et al., 2017).

- Help to understand what exists at present-what are the technologies

- Support in auditing what technologies are present in each of their teaching spaces

- Guidance in how these technologies enhance student learning. 


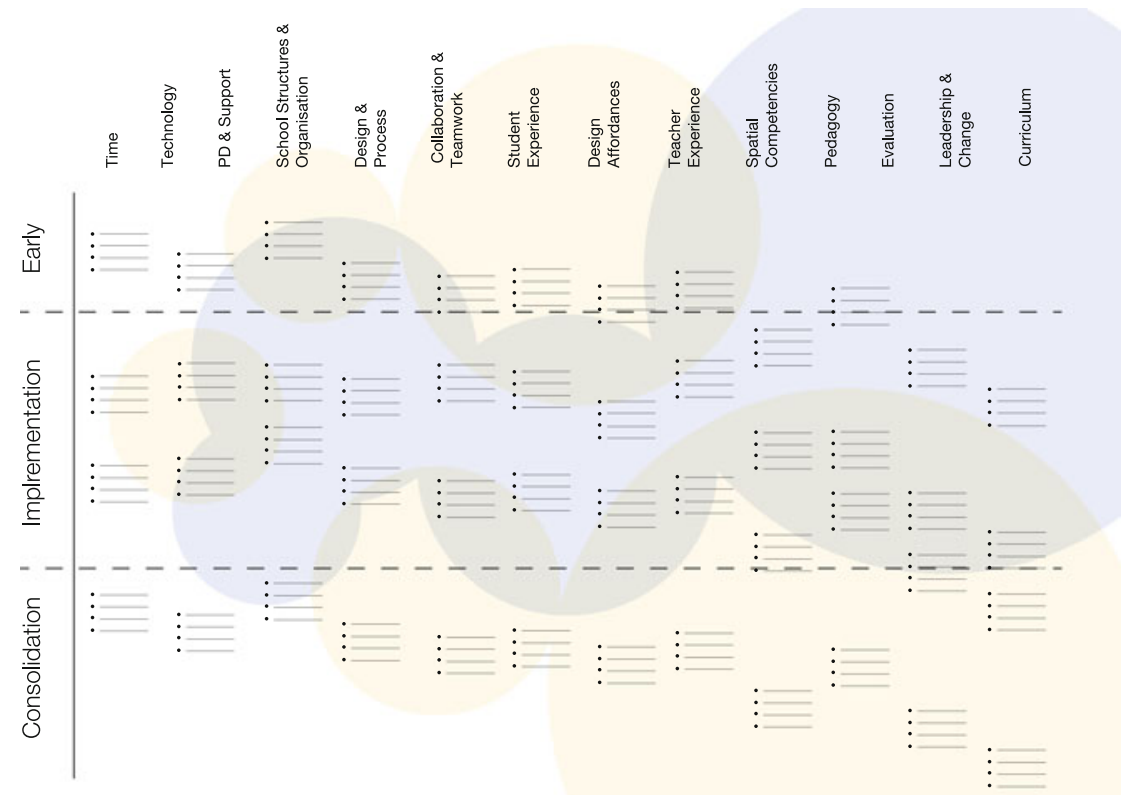

Fig. 5 The transitions pathway, with grand themes added (Copyright the ILETC project)

Teachers need PROFESSIONAL LEARNING (PL) on how to use these spaces well (Mahat et al., 2017).

- PL that is relevant to their existing knowledge and practices

- PL that address and extend their personal teaching philosophy

- PL that is feasible and useful given their schools' budgets and their own available time

- PL that can be put into action immediately

- PL that can be evaluated for impact against teachers' standards.

Teachers seek to improve their pedagogies in ILEs need the support of the STRUCTURE AND ORGANISATION of the school (French et al., 2019).

- Fostering a culture of growth, experimentation without judgement

- Allowing appropriate time for PD, that reflects the importance of supporting change

- Re-interpreting timetables that are adaptable to new ways of teaching

- Challenging subject discipline 'rules' to allow cross-disciplinary experimentation. 
Teachers need to be active agents in the DESIGN PROCESS.

- Opportunity to express their vision for learning (the 'Education Brief').

- Seeing their ideas reflected in the preliminary designs (The Design Brief).

- Having the plans explained and discussed in ways they can understand.

- Establishing methods for implementation of their teaching into the proposed designs.

- Establishing ways to evaluate, across time, if the spaces are fulfilling their expectations for ideal teaching.

- Opportunities for re-design.

Teachers need support in developing visions for, methods of, and opportunities to refine effective COLLABORATIVE PRACTICES. Working together in spaces whether physical or virtual, we know that teachers need strategies to (Bradbeer, 2018)

- TEACH TOGETHER

- THINK TOGETHER

- simply BE TOGETHER.

Teachers need to understand the actual—as opposed to anticipated-STUDENT EXPERIENCE of inhabiting these spaces (Mahat et al., 2017).

- How do these spaces impact student well-being, relationships, feelings of worth?

- How do they foster inclusivity, including opportunities for participation for students with disabilities?

- How do these spaces assist improved student learning outcomes?

Teachers need help in seeing, then using, the anticipated and unanticipated AFFORDANCES of these spaces (Young et al., 2019).

- What did the designers 'build in' that will help quality teaching?

- How can teachers use these to their maximum?

- What of the accidental affordances, those elements that assist better teaching yet often remain unrecognised?

Teachers need support in the 'grammar' of spaces, how they work, and how they can work in these spaces. SPATIAL COMPETENCIES constitute to some degree a form of literacy and require nurturing (Leighton, 2017).

- Do I utilise all the spaces in my environment to their potential?

- Do I develop lessons that utilise space to enhance students' learning experiences and learning outcomes?

Teachers need support in developing PEDAGOGIES that reflect, utilise and leverage off the unique features of their learning space. 
- What is the myriad of approaches available to teachers regarding collaborative practices?

- How can teachers continually evolve, refine, evaluate effective practices in these more flexible, ephemeral spaces.

Teachers need support to EVALUATE the way their use of space impacts student learning.

- Are students doing better or worse than the 'norm' in this environment?

- How do I understand which component of space is having what effect on student learning experiences?

- How can I monitor 'tweaks' to my approach to teaching, to understand what should be developed more, what should be modified?

Teachers need to experience good LEADERSHIP; support for the changes inevitable in good transition to ILEs (Osborne, 2018).

- How can teacher-inclusion be built into the change process?

- How can teachers' epistemological beliefs be incorporated into a more 'collaborative' teacher structure?

- How can teacher voice be represented in the major decisions that are being made?

Teachers need to have their 'spatial opinions and beliefs' represented at the CURRICULAR level.

- If curriculum is the journey, what is the starting point, what is the destination? How does space impact this?

- How do students 'occupy' curriculum in the way they occupy space?

\section{Not a Formula}

Analysis of data gathered from international audiences at ILETC symposia allowed the research team to organise the themes according to when they appeared to most commonly be of relevance; from 'early' in the transition stages (placing those to the left of the Pathway), during 'implementation' of ILEs (situating these to the middle of the Pathway), and into long term 'consolidation' as transition seemingly becomes established, but needs to be continually interrogated (the right).

We argue this arrangement of common themes temporally organised (Early, Implementation, Consolidation), constitutes a common pathway (represented hypothetically in Fig. 6 by the diagonal dotted line). Most schools, and teachers in schools, undertake this type of journey across time, and in the process often engage with issues represented by the themes. We are very keen to point out, however, this does not suggest the existence of an assured formula for good teacher transition. In fact, the more eclectic journeys illustrated by the fluid lines in Fig. 7 represents more accurately the actual experiences of schools and teachers who transit into innovative 


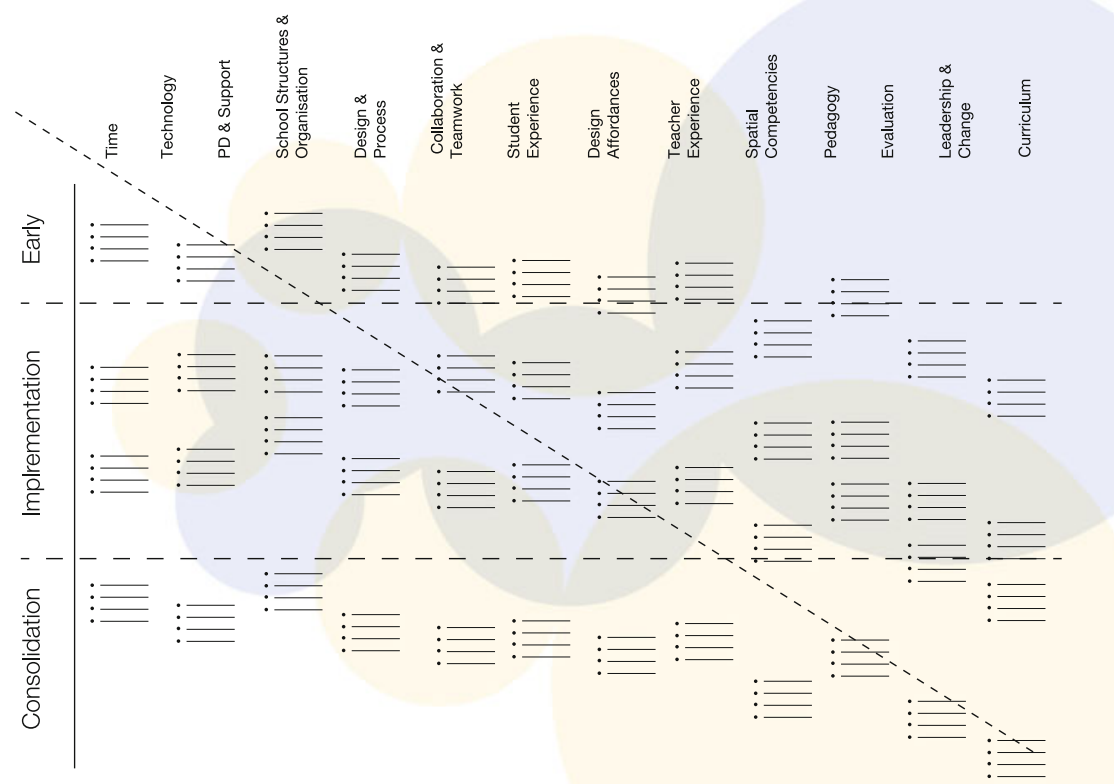

Fig. 6 The transitions pathway, with hypothetical common 'journey' indicated (Copyright the ILETC project)

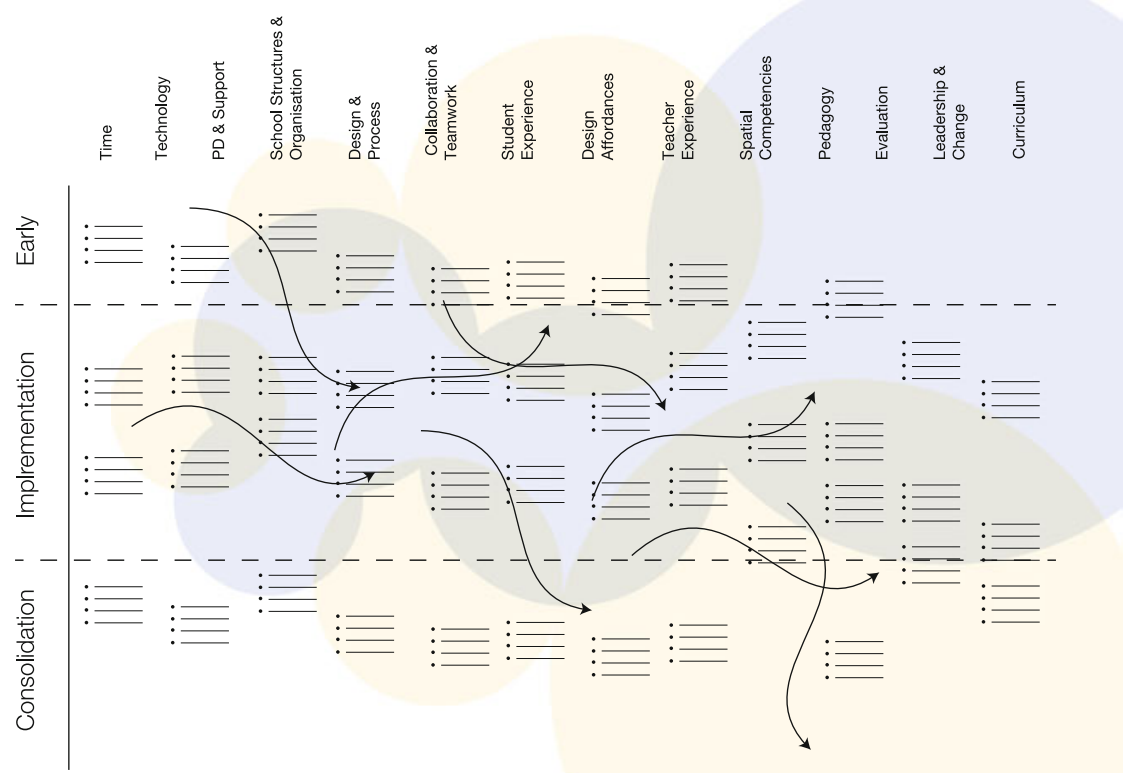

Fig. 7 The Transitions Pathway, with representative individual 'journeys' added (Copyright the ILETC project) 
learning environments. Each starts at a different point and moves in a unique direction. Each has a unique set of needs and purposes. While the journey can be seen to be reasonably common, each school addresses unique spatial needs and each teacher implements often unique pedagogies to meet those needs. This is the reality of the ephemeral nature of modern schooling.

\section{Populating the Pathway}

We began this chapter asking how the papers in this publication give us direction for the 'where to now' question. These and other data sources gathered within ILETC have provided us with a framework for the way teachers are effectively moving into innovative learning environments. Our task now is populating this pathway with actual examples of good practices. Following the Transitions Symposia that was the source of this book, the ILETC team embarked on a complex data collection phase to find and document strategies schools and teachers had conceptualised to use innovative learning environments well, and the tools they built to implement those strategies. To illustrate, Figs. 8 and 9 provide a sample of this.

In this example, that of space and collaboration, schools identified three components-teacher/teacher collaboration, teacher/student collaboration and student/student collaboration (Fig. 8). To focus on the third, a common spatial

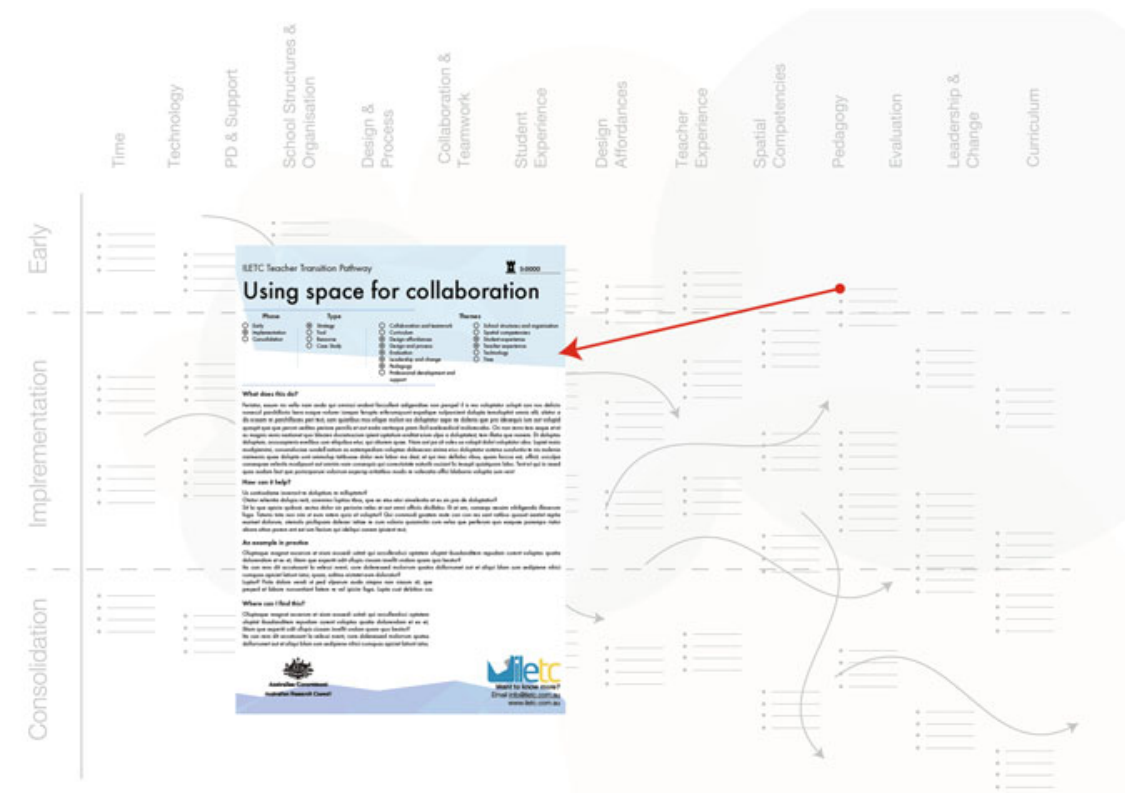

Fig. 8 The Transitions Pathway, with a sample 'strategy' indicated (Copyright the ILETC project) 


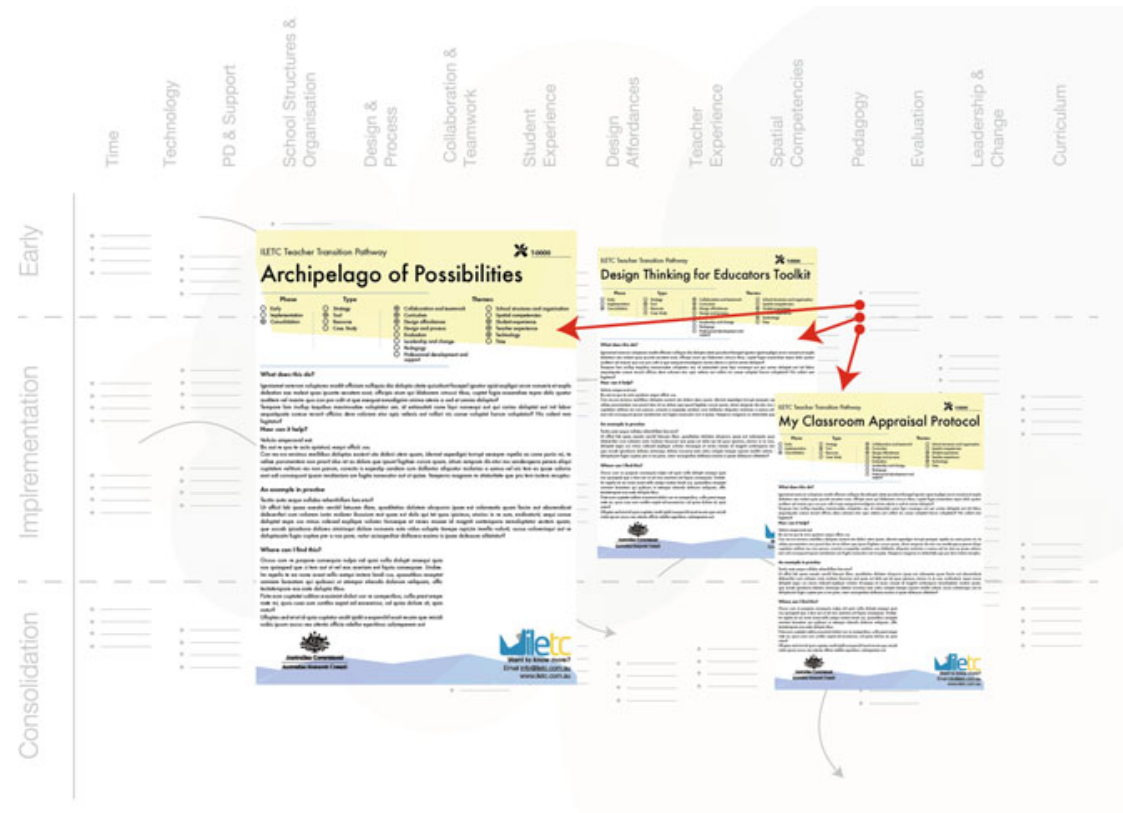

Fig. 9 The Transitions Pathway, with a sample 'tools' added (Copyright the ILETC project)

'problem' was that traditional furniture arrangements restricted this from happening. The reality was that time and effort required to rearrange tables and chairs to facilitate student/student collaboration meant teachers often avoided utilising this valuable affordance.

One 'solution' or a tool developed by some schools saw a simple diagram being placed beside the entry to the space with a number of arrangements graphically illustrated and given labels (Fig. 9). Teachers found that with a simple instruction ("Let's have type G") saw students quickly rearrange furniture in that configuration, and that was as easily reversed at the end of the lesson. The ILETC research team used data from the symposia to decide this spatial teaching strategy and tool was relevant during the implementation and consolidation stages of transition (the $Y$, or temporal axis), and best fitted to the Collaboration and Teamwork, Spatial Competencies and Student Experiences grand themes (across the $X$ axis). It was, therefore, placed in that position in the overall Pathway - one of the myriad 'dots' shown in Fig. 7.

In this way, ILETC has been building the Pathway to organise many strategies and tools developed by teachers as they came to grips with the reality of transitioning into more innovative spaces. At the time of writing this book, the 'population' of the Pathway by documenting teacher practices is well advanced-a tangible, productive output from the theorisation, and applied thinking of the many researchers and teachers who contributed to ILETC. 


\section{Where to Now?}

Assisting teachers to navigate the Pathway is the next challenge. As mentioned earlier, we know (1) that no school or teacher transitions from traditional to innovative spaces in the same way; and (2) often, teachers and schools are not always aware of the spatial components of their actions when seeking best practice; in short, few common spatial concepts are known, terminologies differ, and educators remain unaware of their own 'spatial competencies'. ILETC is now developing two methods of overcoming this problem; (1) a suite of activities or 'wayfinding exercises' that will help teachers understand what they do and don't know in terms of spatial knowledge and practices, and (2) a set of 'spatial typologies' (Fig. 10) that simplify difficult concepts such as types of furniture, acoustics and use of digital technologies in innovative learning environments, in a manner similar to the 'spatial design' and 'spatial pedagogies' illustrated in Figs. 1 and 2. These serve the function of assisting teachers to know what strategies and tools may meet their individual needs.

We would like to finish with a very positive spin from our research. We mentioned at the start of this chapter that the early stages of ILETC sought to understand what actually existed in terms of infrastructure and practices in those spaces. We feel we have a good grasp of that now.

The second objective was to test assumptions we brought to the project. For example, we believed we would need to design strategies and tools to help teachers transit into ILEs. That has been dispelled-our research is identifying a myriad of strategies and tools teachers have developed, either knowingly or unconsciously, as they make the most of their new spaces. These are now being documented and inserted into our Transitions Pathway. There may be gaps, and this forms an opportunity for future inquiry.

Another assumption was the assertion, commonly heard, that teachers were not using these spaces well. They were simply repeating old habits in new environments. The first survey challenged this assumption-the strong correlation between ILEs and high-quality teaching and good student learning demonstrated that good things were happening in these spaces. A second survey, due for publication in the near future, has provided evidence of what teachers were actually doing, their confidence in their skills to adapt to the new spaces, and their desire for particular support to assist this transition. The latter also validated the grand themes in the Transitions Pathway.

\section{A Final Note}

The realisation is that we must trust the competence of our teachers and provide them with the support they require to transit into these spaces. The Spatial Transitions Pathway is one way of doing this at the micro level, the actual practice of 


\section{ILETC Spatial Typologies}

Design

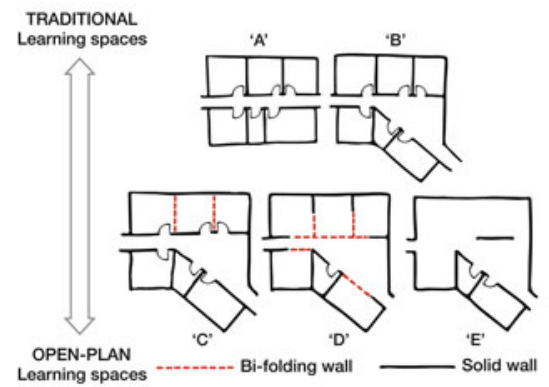

\section{Pedagogy}

Direct instruction Teacher facilitated Teacher facilitated $\infty$ small groups group discussion
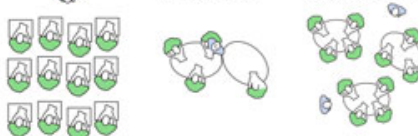

बि 89

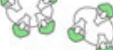

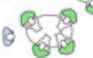

Collaborative w/ teacher support

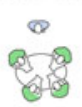

G

One-on-one Individual learning

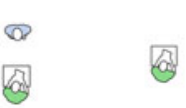

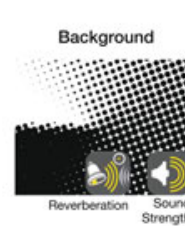

Furniture
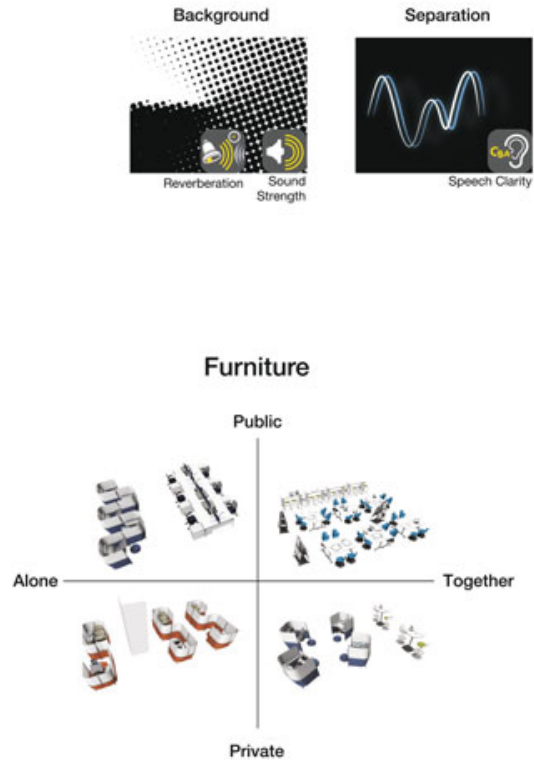

Acoustics
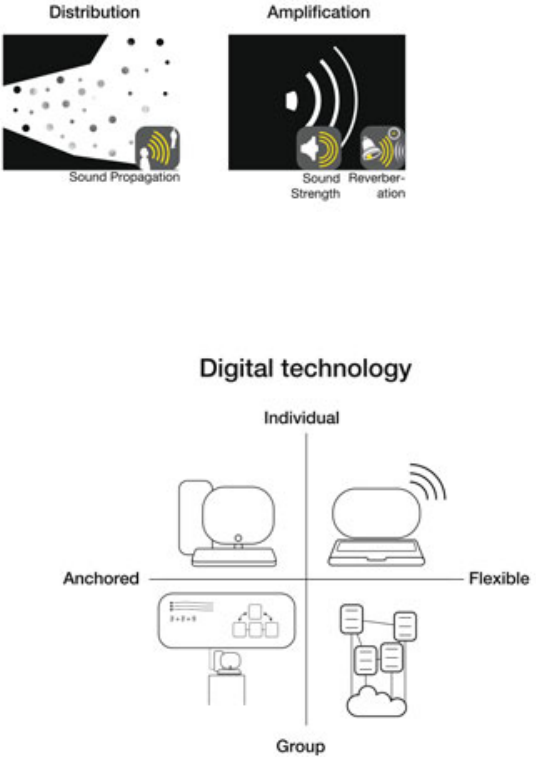

Fig. 10 The five spatial typologies (Copyright the ILETC project) 
teaching in these spaces. However, in terms of the broader picture, we are challenged with a huge task in matching our dollar investment with teacher support. The latter is less visible, there are no shiny surfaces and beautiful vistas to show for that investment, but how teachers actually use these spaces will ultimately justify (or condemn) every penny spent. More research, such as shown in these pages by graduate researchers and talented early career researchers, is required. These buildings are, after all, predominately about the practices that occur within, and it is that knowledge that we must access.

Acknowledgements Material presented in this chapter is the product of work done by the whole ILETC team including its researchers, its seven Ph.D. students, and its two Research Fellows. Special thanks are offered to Steelcase Furniture, Ecophon (Sweden), and Microsoft Education. The authors are indebted to ILETCs Project Manager Joann Cattlin for her support during this research.

\section{Further Reading}

ILETC research outputs mentioned in this chapter (and upcoming outputs) are and will be available online. Requests for access are encouraged via this chapter's authors.

\section{References}

Biggs, J. B. (1987). Student approaches to learning and studying. Research Monograph. Australian Council for Educational Research.

Bradbeer, C. (2018). Enacting teacher collaboration in innovative learning environments. In W. Imms \& M. Mahat (Eds.), Transitions 2018: Continuing the Conversation, Proceedings of International Symposia for Graduate and Early Career Researchers in Australasia, Europe and North America. http://hdl.handle.net/11343/227598.

Bradbeer, C., Mahat, M., Byers, T., \& Imms, W. (2019). A systematic review of the effects of innovative learning environments on teacher mind frames. Innovative Learning Environments and Change. http://www.iletc.com.au/publications/reports.

Bruckner, M. (1997). Eavesdropping on change: Listening to teachers during the first year of an extended block schedule. NASSP Bulletin, 81(593), 42-52.

Byers, T., Mahat, M., Liu, K., Knock, A., \& Imms, W. (2018). A systematic review of the effects of learning environments on student learning outcomes. Innovative Learning Environments and Change. http://www.iletc.com.au/publications/reports.

Commonwealth of Australia. (2010). Building the education revolution. http://web.archive.org/ web/20100417041604/http:/www.deewr.gov.au:80/schooling/buildingtheeducationrevolution/ Pages/default.aspx.

French, R., Imms, W., \& Mahat, M. (2019). Case studies on the transition from traditional classrooms to innovative learning environments: Emerging strategies for success. Improving Schools. https:// doi.org/10.1177/1365480219894408.

Goss, P. (2016, January 22). Should you worry about a schools shortage? It really depends on where yоu live. Conversation. https://theconversation.com/should-you-worry-about-a-schoolsshortage-it-really-depends-on-where-you-live-53296.

Hattie, J. (2009). Visible learning: A synthesis of over 800 meta-analysis relating to achievement. London: Routledge.

Hattie, J. (2012). Visible learning for teachers: Maximizing impact on learning. London: Routledge. 
Holland, K. (2017, June 28). Major crisis in Australian public school infrastructure. Retrieved from https://www.wsws.org/en/articles/2017/06/28/infra-j28.html.

ILETC. (2018). Phase one report 2016-2017. Innovative Learning Environments and Teacher Change. http://www.iletc.com.au/wp-content/uploads/2018/06/ILETC-Phase-1-reportpublished.pdf.

Imms, W., Cleveland, B., \& Fisher, K. (Eds.). (2016). Evaluating learning environments: Snapshots of emerging issues, methods and knowledge. Rotterdam, The Netherlands: Sense Publishers.

Imms, W., \& Mahat, M. (Eds.). (2017). Transitions Australasia: What is needed to help teachers better utilize space as one of their pedagogic tools. Innovative Learning Environments and Teacher Change. http://www.iletc.com.au/publications/proceedings/.

Imms, W., \& Mahat, M. (Eds.). (2018a). Transitions Europe: What is needed to help teachers better utilize space as one of their pedagogic tools. Innovative Learning Environments and Teacher Change. http://www.iletc.com.au/publications/proceedings/.

Imms, W., \& Mahat, M. (Eds.). (2018b). Transitions North America: What is needed to help teachers better utilize space as one of their pedagogic tools. Innovative Learning Environments and Teacher Change. http://www.iletc.com.au/publications/proceedings/.

Imms, W., \& Mahat, M. (Eds.). (2019). What are teachers doing (well) when transitioning from traditional classrooms to innovative learning environments? Innovative Learning Environments and Teacher Change. http://www.iletc.com.au/publications/proceedings/.

Imms, W., Mahat, M., Byers, T., \& Murphy, D. (2017). Type and use of innovative learning environments in Australasian Schools-ILETC Survey 1. Innovative Learning Environments and Teacher Change. http://www.iletc.com.au/publications/reports.

Leighton, V. (2017). Teaching space: Does a teacher's spatial competency affect their teaching and effect the different types of learning that takes place in a classroom? In W. Imms \& M. Mahat (Eds.), Transitions Symposium Proceedings Australasia 2017 (pp. 57-63). Innovative Learning Environments and Teacher Change. http://hdl.handle.net/11343/198087.

Mahat, M., Bradbeer, C., Byers, T., \& Imms, W. (2018). Innovative learning environments and teacher change: Defining key concepts. Innovative Learning Environments and Teacher Change. http://www.iletc.com.au/publications/reports.

Mahat, M., Bradbeer, C., Cattlin, J., \& Imms, W. (2019). Validating the ILETC's teacher transition pathway. In W. Imms \& M. Mahat (Eds.), What are teachers doing (well) when transitioning from traditional classrooms to innovative learning environments? (pp. 13-26). Innovative Learning Environments and Teacher Change. http://www.iletc.com.au/publications/proceedings/.

Mahat, M., Grocott, L., \& Imms, W. (2017). "In the real world...”: Teachers' perceptions of ILEsILETC Phase 1 teacher workshops. Innovative Learning Environments and Teacher Change. http://www.iletc.com.au/publications/reports.

Mahat, M., \& Imms, W. (2020). Establishing a reliable measure of perceptions of teacher and student use of learning environments. The Australian Education Researcher. https://doi.org/10.1007/s13 384-020-00382-z.

Osborne, M. (2018). Change leadership and the transition to innovative learning environments. In W. Imms \& M. Mahat (Eds.). What are teachers doing (well) when transitioning from traditional classrooms to innovative learning environments? (pp. 157-161). Innovative Learning Environments and Teacher Change. http://www.iletc.com.au/publications/proceedings/.

Young, F., Cleveland, B., \& Imms, W. (2019). The affordances of innovative learning environments for deep learning: educators' and architects' perceptions. The Australian Educational Researcher (pp. 1-28). https://doi.org/10.1007/s13384-019-00354-y.

Wesley Imms (Australia) comes to learning environments research from a long period as a teacher, then through a Ph.D. in Curriculum Studies from the University of British Columbia in Canada. His teaching spanned art and design education, his practice for decades has included designing and building 'crafted' homes, and his art works have focused on bespoke purposeful furniture construction, which he exhibits annually. For the last decade these interests have 
conflated into applied research programmes, where he specialises in assisting schools to conceptualise, inhabit, refine and evaluate learning environments. This work has focused extensively on large-scale collaborative projects that draw heavily on international industry participation, and with an emphasis on Ph.D. and Masters level input to this knowledge generation. He is a co-Director of the LEaRN group, manages LEaRN@MGSE, and through selected consultancies he works closely with schools in the Asia-Pacific region on improving the use of innovative learning environments. Wesley is currently an Associate Professor at The University of Melbourne, Australia.

Marian Mahat (Australia) is a Senior Research Fellow at The University of Melbourne. She has more than twenty years of professional and academic experience, spanning several universities, the Australian Federal and local governments, as well as the private sector. Drawing on multiple fields of inquiry, her work focuses on student learning and outcomes in various educational contexts, innovative quantitative and qualitative methodologies and interdisciplinary collaboration. She is the lead Research Fellow and Research Manager of the Innovative Learning Environments \& Teacher Change Project 2016-2020 and works with Australian and New Zealand schools to implement a 'capacity building' programme to support teachers effective use of space as a pedagogical tool.

Open Access This chapter is licensed under the terms of the Creative Commons Attribution 4.0 International License (http://creativecommons.org/licenses/by/4.0/), which permits use, sharing, adaptation, distribution and reproduction in any medium or format, as long as you give appropriate credit to the original author(s) and the source, provide a link to the Creative Commons license and indicate if changes were made.

The images or other third party material in this chapter are included in the chapter's Creative Commons license, unless indicated otherwise in a credit line to the material. If material is not included in the chapter's Creative Commons license and your intended use is not permitted by statutory regulation or exceeds the permitted use, you will need to obtain permission directly from the copyright holder.

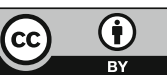

